\title{
A Plausible Antibacterial Green Synthesized AgNPs from Tridax procumbens Leaf-flower Extract
}

\author{
Jesse Joel T.* and Jesvin Shobini \\ Department of Biotechnology, Karunya Institute of Technology and Sciences, Karunya Nagar, \\ Coimbatore - 641 114, India.
}

\begin{abstract}
The current study was aimed at the green synthesis of silver nanoparticles (AgNPs) from leaf-flower and flower extracts of Tridax procumbens which are effective against oral pathogens and its characterization. The silver nanoparticle attaches to the cell membrane of bacteria and disturbs its function by penetrating inside bacterial cell by releasing silver ions and inhibits the bacterial growth. The silver nanoparticles obtained from the bio-reduction method using leaf-flower and flower extract with silver nitrate was characterized using UV- visible spectroscopy (UV-Vis), X-Ray Diffraction (XRD), Fourier Transform Infra-Red spectroscopy (FTIR), Scanning Electron Microscope (SEM). The presence of AgNPs in the aqueous extract was confirmed by the yellowish-brown color change of the extract and by Surface Plasmon Resonance (SPR) peaks in the UV- Visible spectroscopy (430nm-510nm) analysis, X-Ray Diffraction (XRD) for Functional groups, Fourier Transform Infra-Red spectroscopy (FTIR) for Phytophenols $(3448.72 / \mathrm{cm})$. Scanning Electron Microscope (SEM) showed particle range $33-45 \mathrm{~nm}$ and particle size analysis using Zeta potential (142.2 (d.nm). The other analysis showed that the AgNPs were irregularly shaped, crystalline in nature and less stabilized due the effect of capping agents in the extracts. In this study, the antibacterial activity of these nanoparticles was tested against the oral pathogens. The antibiotic resistance in pathogenic microbes has led to the emergence of multidrug-resistant (MDR) pathogens. Therefore, the Leaf-flower combination was seen as plausible antibacterial agent in the prevention of Dental caries and can be used as an additive in Tooth paste or mouth freshners.
\end{abstract}

Keywords: Antibacterial, green synthesis, Tridax procumbens, Leaf flower.

*Correspondence: jessejoel@gmail.com; +919487733707

(Received: 10 October 2018; accepted: 20 November 2018)

Citation: Jesse Joel T. and Jesvin Shobini, A Plausible Antibacterial Green Synthesized AgNPs from Tridax procumbens Leaf-flower Extract, J Pure App/ Microbiol., 2018; 12(4):2135-2142. http://dx.doi.org/10.22207/JPAM.12.4.51

(c) The Author(s) 2018. Open Access. This article is distributed under the terms of the Creative Commons Attribution 4.0 International License which permits unrestricted use, sharing, distribution, and reproduction in any medium, provided you give appropriate credit to the original author(s) and the source, provide a link to the Creative Commons license, and indicate if changes were made. 


\section{INTRODUCTION}

Over the past few decades, antibiotics have been widely employed against different types of pathogenic micro-organisms for treatment of different infections or diseases. Due to continuous usage of antimicrobial drugs in treating different infections or diseases has led to the increase in antibiotic resistance in various strains of microbes. Antibiotic resistance or Multidrug resistance (MDR) is a natural phenomenon that occurs in microbes over the time. MDR can be defined as a pathogenic microbe which was previously sensitive to certain antibiotics but has become resistant or insensitive against it. This can lead to secondary infections in immunocompromised patients suffering from HIV infection, cancer or tumors, severe burn injuries, diabetic patients etc. This has led to difficulty in treating immunocompromised patients with secondary infections by making the treatment ineffective and long duration. This makes the treatment expensive and can even worsen the condition of patients who are not able to afford it ${ }^{1,2}$. Therefore, there is an increasing need in finding an effective and inexpensive alternate treatment method to deal with MDR in pathogenic microbes.

Nanoparticles (NPs) have been considered as a new antimicrobial agents and is being continuously studied by researchers ${ }^{3}$. Nanoparticles are smaller in size approximately ranging from 1 to $100 \mathrm{~nm}$. It can be synthesized by three methods: physical, chemical and biological. The biological method is eco-friendly, less time consuming and inexpensive compared to the other methods. It is effective and has an ecofriendly process for synthesis, making it a promising area of study in nanotechnology. The synthesis of nanoparticles using plant extract, due to its ecofriendly nature has been termed as "Green Synthesis". The properties of NPs vary based on its different sizes and shapes which influences its surface to volume ratio. For more than 500 years, silver $(\mathrm{Ag})$ and gold $(\mathrm{Au})$ have been used in siddha medicine in different proportions and ingredients for the treatment of certain diseases ${ }^{4,5}$. This has led to increase in studying the synthesis of gold and silver nanoparticles and its various properties by researchers for the past few years. The advantage of silver nanoparticles (AgNPs) over gold nanoparticles (AuNPs) is that it has inhibitory effect on microbes and is less expensive ${ }^{6}$.

Since ancient times, Tridax procumbens Linn has been used as a medicinal plant in India. It has been reported to have antimicrobial, anti-inflammatory, antidiabetic, antipyretic, haemostatic, hepatoprotective, immunomodulator and antioxidant properties ${ }^{7,8}$. It belongs to the family Asteracea which is commonly known as Gharma and coat buttons in English which is native to tropical America. In this plant, the phytochemicals reported are carotenoids, flavonoids, alkaloids, tannins, $\beta$-sitosterol, n-hexane, fumaric acid, luteolin, quercin, oxoester, lauric acid, myristic, palmitic acid, arachidic and linolenic acid ${ }^{9,10}$. Extracts of various parts of Tridax procumbens $L$. have been studied for its properties as antibacterial, antifungal, anticandidal etc. but still leaf-flower extract combination has not yet been studied against microbes and for synthesis of AgNPs. Also, Tridax procumbens L. leaf and other part extracts NPs have not yet been studied against oral pathogens ${ }^{1,11-13}$. One of major health problems like dental caries, gum infections etc. are caused by oral pathogens like Streptococcus mutans, Streptococci species, Lactobacillus acidophilus, Enterococcus faecalis, Bacillus mojavensis, lactobacillus casei etc. The dental caries is formed or caused due to plaques or bacterial biofilm on the teeth ${ }^{14}$. AgNPs releases silver ions which penetrates the bacterial cell wall and disrupts DNA replication leading to bacterial cell death ${ }^{15}$. Therefore, the current study was aimed at synthesizing silver nanoparticles using leaf-flower and flower extract and to study the properties of AgNPs using different instrumental techniques followed by the analysis of antibacterial activity against oral pathogens.

\section{MATERIALS AND METHODS}

\section{Sample Collection and Preparation of leaf-flower} and flower extracts

Fresh and healthy leaves with flowers and on the other hand only flowers were collected from Karunya Institute of Technology and Sciences, Coimbatore, Tamil Nadu. It was washed thoroughly with tap water and then with distilled water. 10 grams each of leaf-flower and only flower was weighed and suspended in $100 \mathrm{ml}$ of double distilled water. It was kept for boiling in hot water bath at $60^{\circ} \mathrm{C}$ for 45 minutes $^{16}$. 
Preparation of $1 \mathrm{mM}$ Silver Nitrate solution

Silver nitrate $\left(\mathrm{AgNO}_{3}\right)$ of analytical grade (GM409) was purchased from HiMedia Laboraties Pvt Ltd, Mumbai. Silver nitrate solution of $1 \mathrm{mM}$ was prepared by adding 0.07 grams of silver nitrate in $450 \mathrm{ml}$ of distilled water.

\section{Preparation of Silver Nanoparticles}

A $50 \mathrm{ml}$ of leaf-flower and flower extracts each were added separately to $1 \mathrm{mM}$ silver nitrate solution. It was kept in dark room undisturbed for 24 hrs.

\section{Characterization of AgNPs}

The UV-Visible spectroscopy analysis was carried for the aqueous extracts of AgNPs synthesized from leaf-flower and flower extract using Hitachi double beam spectrophotometer (Model U-2910) between the range 200-300nm. Further, the sample extracts were centrifuged at $10,000 \mathrm{rpm}$ for 20 mins. The supernatant was discarded and the pellets were kept for drying in hot air oven. The dried samples on the petriplates were scraped in order to get a powdered sample and stored in eppendorf tubes. These powdered samples were used for SEM analysis using JEOL Scanning Electron Microscope JSM 6390 (Japan) under X40,000 and X55,000 at 20kV. The powdered sample was also subjected to XRD analysis using XRD-6000 (Shimadzu, Japan). Also, FTIR analysis was carried out on the dried nanoparticles between the spectral ranges $450-4000 / \mathrm{cm}$. This was followed by particle size analysis using Zeta Sizer Nano ZS90 (Malvern Instruments, UK) to study the surface and size distribution pattern of the AgNPs synthesized ${ }^{12,16}$. The all of the above instrumental facilities were availed from Karunya Institute of Technology and Science (KITS), Coimbatore, Tamil Nadu.

\section{Inoculum preparation}

The bacterial cultures used for the determination of antibacterial activity were Oral isolate-1(Gram positive Streptococci), Oral isolate-2 (Gram positive Lactobacilli), Bacillus mojavensis and Enterococcus faecalis. The inoculum for the bacterial cultures were prepared by taking 2-3 colonies of the four bacterial strains into each $5 \mathrm{ml}$ of Brain Heart Infusion broth and was kept in shaker at $150 \mathrm{rpm}\left(35^{\circ} \mathrm{C}\right)$ for $2-4 \mathrm{hrs}$. Antibacterial activity of AgNPs

The antibacterial activity was assessed using Agar well diffusion method. The Mueller Hinton agar media was procured from HiMedia Laboratories Pvt Ltd. Freshly prepared Mueller Hinton agar was autoclaved at 15 psi for 15 20 mins at $121^{\circ} \mathrm{C}$. The media was poured into sterilized petriplates and was allowed to cool down at room temperature in Laminar Air Flow. After solidification, the bacterial cultures was swabbed on the agar plates and the wells were bored in the agar approximately of $3 \mathrm{~mm}$ depth for the inoculation of AgNPs synthesized from the aqueous extract of leaf-flower and flower with sterile distilled water as negative control. After the inoculation of Aqueous extract with AgNPs, the agar plates were incubated for $24 \mathrm{hrs}$ at $37^{\circ} \mathrm{C}$ and the zone of inhibition around the well was observed $^{17}$.
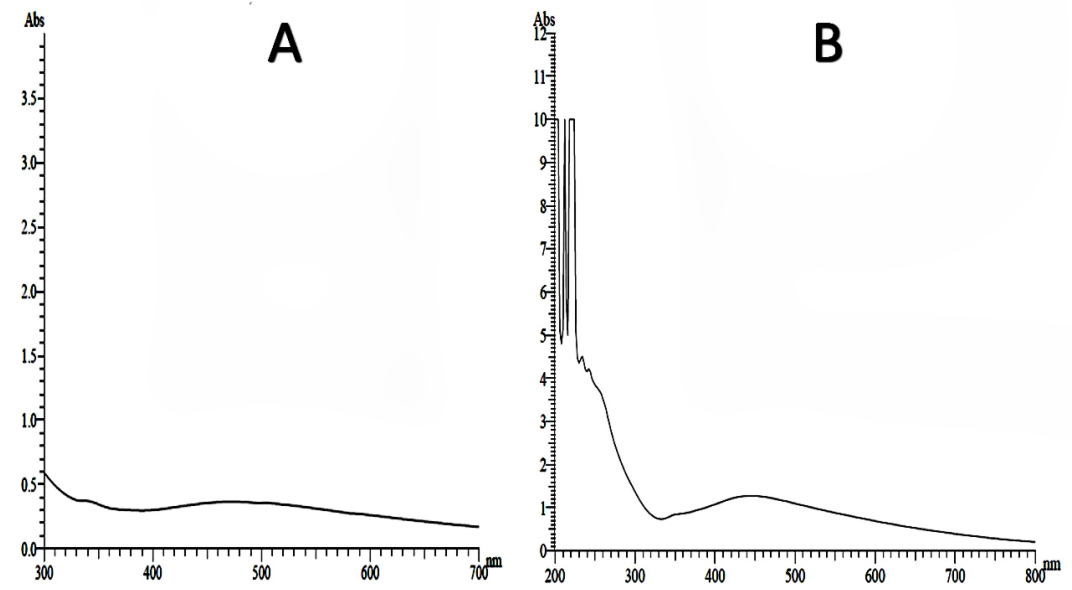

Fig. 1. UV-Vis spectra of silver nanoparticles formation by Tridax procumbens (A) leaf-flower extract and (B) flower extract. 


\section{RESULTS AND DISCUSSION}

There has been an ever-increasing need for alternate treating methods of infections or diseases due to antibiotic resistance. Metal nanoparticles have been known to have medical applications like drug production, bio-sensing etc. Metal nanoparticles can be synthesized by physical, chemical and biological methods. The physical and chemical methods for involves top- down and bottom approach. These methods produce hazardous byproducts in large quantity whereas the biological method is ecofriendly and does not produce hazardous byproducts. Also, the Tridax procumbens plant extracts contains phytochemicals, minerals, vitamins and fibers which have therapeutic properties. Therefore, the present study was aimed at green synthesis of silver nanoparticles and to study its properties.

The yellowish-brown color change

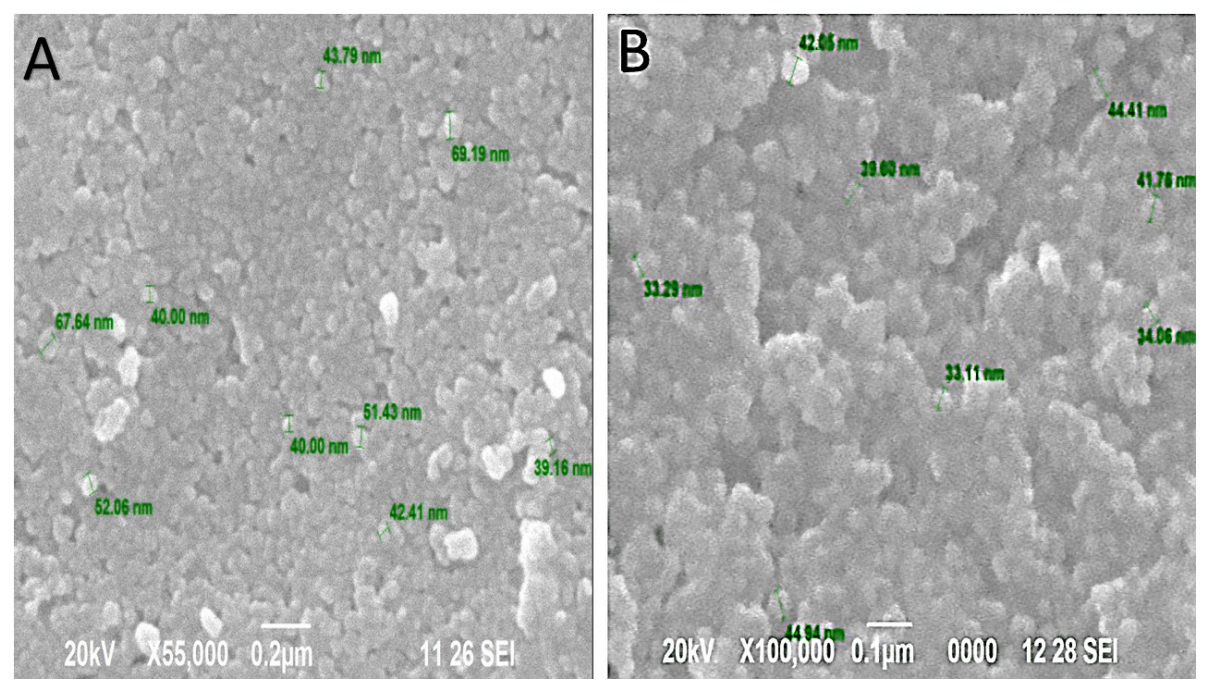

Fig. 2. Scanning Electron Microscopic image of AgNPs synthesized using Tridax procumbens (A) leaf-flower and (B) flower extract

Table 1. Zone of inhibition ( $\mathrm{mm}$ ) of AgNPs formed using leaf-flower and flower extracts

\begin{tabular}{|c|c|c|c|c|c|}
\hline $\begin{array}{l}\text { S. } \\
\text { No. }\end{array}$ & Isolates & $\begin{array}{l}\text { AgNPs } \\
\text { Sample }\end{array}$ & $\begin{array}{l}\text { Concentrations } \\
\text { (\%) }\end{array}$ & $\begin{array}{l}\text { Zone of } \\
\text { Inhibition (in mm) }\end{array}$ & $\begin{array}{l}\text { Negative } \\
\text { Control }\end{array}$ \\
\hline \multirow[t]{4}{*}{1} & Oral isolate 1 & Leaf-flower extract & 70 & $10 \pm 0.98$ & - \\
\hline & (Streptococcus spp.) & & 100 & $15 \pm 0.19$ & \\
\hline & & Flower & 70 & $8 \pm 0.46$ & \\
\hline & & & 100 & $14 \pm 0.58$ & \\
\hline \multirow[t]{4}{*}{2} & Oral isolate 2 & Leaf-flower & 70 & $12 \pm 0.65$ & - \\
\hline & (Lactobacillus spp.) & & 100 & $14 \pm 0.82$ & \\
\hline & & Flower & 70 & $10 \pm 0.11$ & \\
\hline & & & 100 & $12 \pm 0.23$ & \\
\hline \multirow[t]{4}{*}{3} & Bacillus spp. & Leaf -flower & 70 & $10 \pm 0.28$ & - \\
\hline & & & 100 & $12 \pm 0.45$ & \\
\hline & & Flower & 70 & $8 \pm 0.17$ & \\
\hline & & & 100 & $11 \pm 0.55$ & \\
\hline \multirow[t]{4}{*}{4} & Enterococcus spp. & Leaf-flower & 70 & $13 \pm 0.34$ & - \\
\hline & & & 100 & $14 \pm 0.12$ & \\
\hline & & Flower & 70 & $11 \pm 0.78$ & \\
\hline & & & 100 & $13 \pm 0.33$ & \\
\hline
\end{tabular}


observed after addition of leaf-flower and flower extract separately to $1 \mathrm{mM} \mathrm{AgNO}_{3}$ solution, shows the presence of AgNPs formation. This color change is due to the excitation of Surface Plasmon Resonance (SPR) of AgNPs synthesized which can also be clearly observed as a peak in the UV-Visible spectroscopy graph. The SPR is caused due to collective oscillations of the conduction electrons of the AgNPs upon irradiation with ultraviolet and visible lights. The SPR is greatly influenced by the particle size, shape, dielectric constant of the medium and adsorbed species (i.e., NPs). The
UV-Visible spectroscopy (Fig. 1) show that the leaf-flower extract synthesized AgNPs in lesser concentrations compared to the flower extract. The formation of peak from $400 \mathrm{~nm}$ to $500 \mathrm{~nm}$ indicates the presence of NPs. The peak for leafflower extract AgNPs ranges from $430 \mathrm{~nm}$ to $510 \mathrm{~nm}$ which is not sharp but indicates that less amount of AgNPs have been formed. Whereas for flower extract the peak ranges from $400 \mathrm{~nm}$ to $500 \mathrm{~nm}$ which is sharp and clear ${ }^{1,12}$.

Further, SEM analysis (Fig. 2) was carried out which helped in studying the structure of the
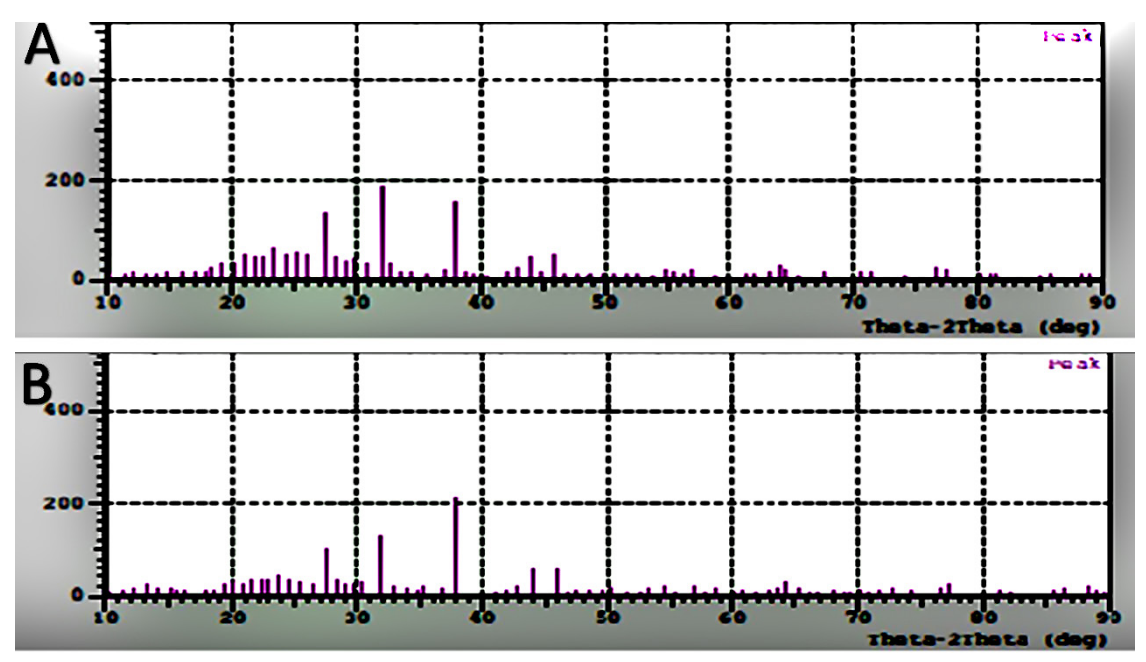

Fig. 3. XRD patterns of AgNPs synthesized using Tridax procumbens (A) leaf-flower and (B) flower extract

AgNPs synthesized using leaf-flower and flower extract. The AgNPs formed in leaf-flower extract with $1 \mathrm{mM}$ of $\mathrm{AgNO}_{3}$ size ranges from 39-69 $\mathrm{nm}$ which is irregular in shape and size. Whereas, the AgNPs formed in flower extract with $1 \mathrm{mM} \mathrm{AgNO}_{3}$ size ranges from $33-45 \mathrm{~nm}$ which also irregular in shape and size. The AgNPs formed by leaf-flower extract is larger in size than the AgNPs formed in flower extract which might be due to the combination of leaf and flower extract. But the flower extract AgNPs have higher size to volume ratio compared to leaf-flower extract AgNPs. The $X$-Ray Diffraction study has confirmed the presence of AgNPs.

The FTIR spectrum study has helped in identifying the functional groups present on the surface AgNPs formed in the aqueous extract of leaf-flower and flower with $1 \mathrm{mM} \mathrm{AgNO}_{3}$. The spectrum region $400-1400 / \mathrm{cm}$ is termed as the fingerprint regions where different functional groups peaks overlap each other and are difficult to interpret. The diffraction pattern can be observed where the Braggs reflection $2 \mathrm{~h}=27.5$, $32,38,44$ is indexed to the (111), (200), (220) and (300) orientations or sets of lattice planes (Fig. 3) The intensity of the peaks and orientations clearly indicates that the AgNPs formed using leaf-flower and flower extracts are face-centered cubic structures. Hence, the AgNPs are crystalline in nature and smaller in size $\mathrm{1}^{1,12}$.

From Fig. $4(A)$, it can be interpreted that the absorption peak at $1583.56 / \mathrm{cm}$ and $2378 / \mathrm{cm}$ shows the presence of secondary amine groups. The absorption peaks at $2976.16 / \mathrm{cm}$ and 3431.36 shows the presence of hydroxyl groups (O-H group) which confirms the presence of phytophenols. 

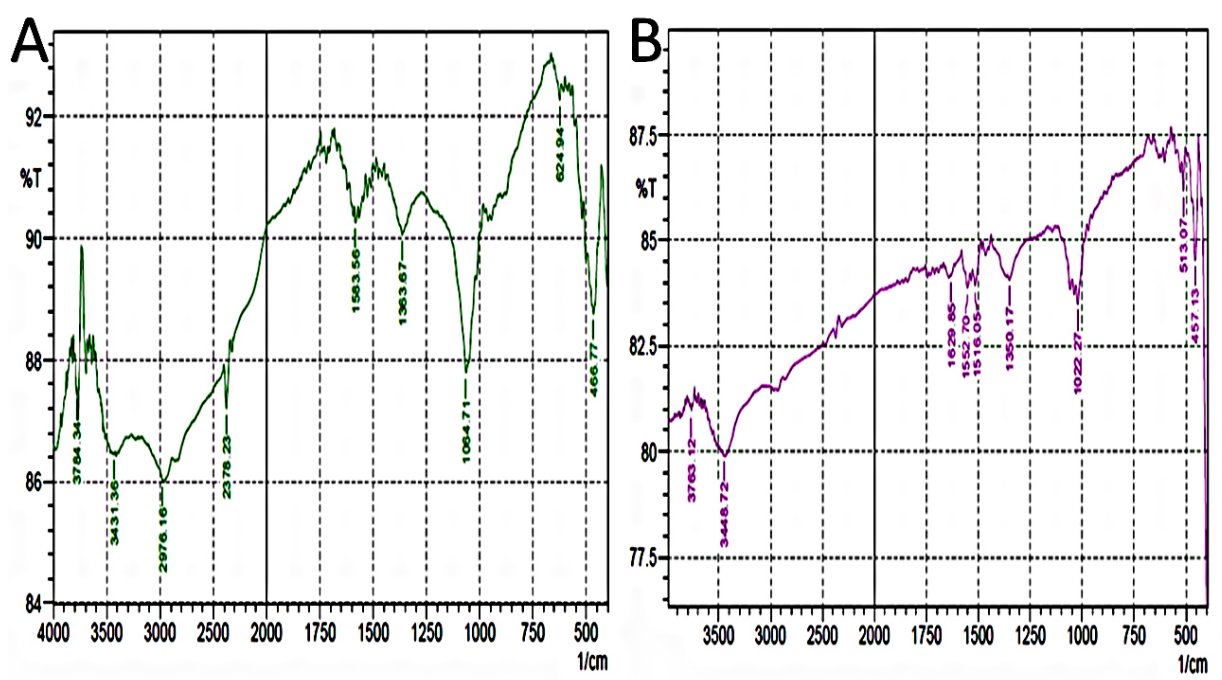

Fig. 4. FTIR absorption spectrum of AgNPs formed by a reduction in $\mathrm{AgNO}_{3}$ ions using Tridax procumbens (A) leaf-flower and (B) flower extract

Whereas the absorption peak at $3784 / \mathrm{cm}$ indicates the stretching of amide (N-H) groups. From Fig. 4 (B), the presence of secondary amines ( $\mathrm{N}-\mathrm{H}$ groups) is confirmed by absorption peaks at $1516.05 / \mathrm{cm}$ and $1552.7 / \mathrm{cm}$, whereas the presence of primary amines or native proteins can be observed at absorption peak at $1629.85 / \mathrm{cm}$. The presence of phytophenols is confirmed by absorption peak at $3448.72 / \mathrm{cm}$ which indicates hydroxyl group $(\mathrm{O}-\mathrm{H})$. Also, amide group stretching is observed at 3763.12/cm absorption peak. Therefore, from FTIR spectrum analysis it can be inferred that the presence of terpenoids, flavonones, phytophenols, proteins etc. can be confirmed in both the aqueous extract of the AgNPs. The functional groups confirmed in this FTIR analysis have been reported previously with AgNps synthesized from leaf and stem extracts ${ }^{1,12,13}$. Hence, it can be concluded that the leaf-flower and flower extracts act as reducing and capping agents for the formation of AgNPs.
A

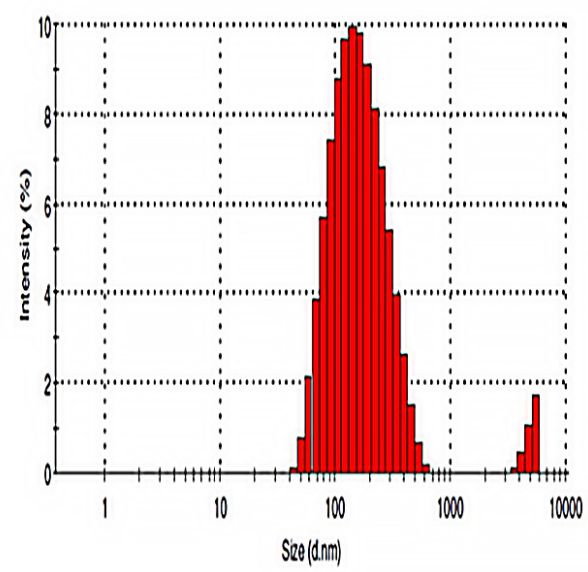

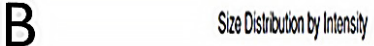

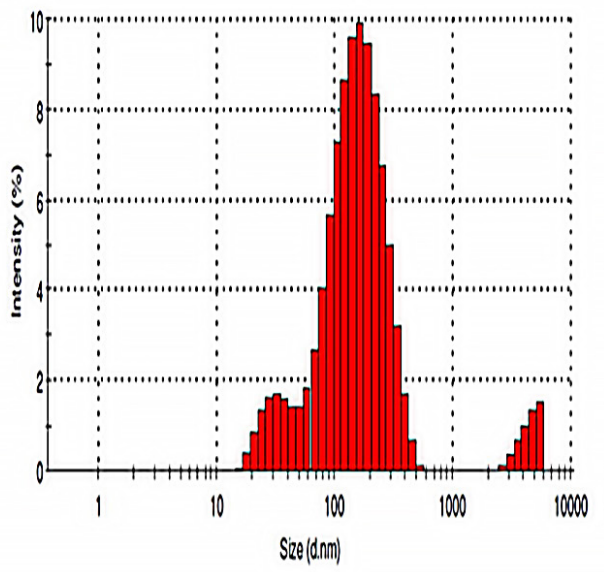

Fig. 5. Particle size analysis using zeta potential for AgNPs formed using (A) leaf-flower and (B) flower extract 
The particle size analysis (Fig. 5) using zeta potential was studied which showed the size distribution and stability of synthesized AgNPs using leaf-flower and flower extracts where three peaks were measured and Z-Average was taken. The Z-Average from AgNPs from leaf-flower extract was 142.2 (d.nm) whereas for AgNPs from flower was 119.8 (d.nm). The Z-Average value for AgNPs from flower extract is less compared to leafflower extract which confirms the data obtained from SEM analysis. The agglomeration of AgNPs from the leaf-flower extract is less compared to AgNPs from flower extract which is due to the phytocomponents present in the sample that acts as a capping agent. Therefore, the stability of the AgNPs from the flower extract is more than AgNPs from the leaf-flower extract ${ }^{1,16}$.

The AgNPs synthesized showed antibacterial activity against oral pathogens which was confirmed by the zone of inhibition around the wells with different sizes or diameter. The zone of inhibition is in circular shape since the AgNPs in the aqueous extract were spread or diffused radially in the agar around the wells.

The zone of inhibition exhibited by the AgNPs in the leaf-flower and flower extract is tabulated in Table 1 with the negative controls.

The leaf-flower extract AgNPs have been observed to show more zone of inhibition compared to the AgNPs in flower extract. This might be due to the flower and leaf extracts combination i.e., it shows synergistic effects as the AgNPs synthesized from the leaf extracts of Tridax procumbens $L$. has already been reported to show antibacterial activity ${ }^{11,18}$. The AgNPs in the leaf-flower extract was found to be effective against in the following order: Oral isolate 1 and 2 (Gram positive organisms, preliminarily isolated by our team and sent for Identification), Enterococcus spp. and Bacillus spp.

\section{CONCLUSION}

In this study, the AgNPs were successfully synthesized using Tridax procumbens leaf-flower and flower extract. The formation of AgNPs in the leaf-flower and flower extract was confirmed by the yellowish-brown color change observed after addition of $1 \mathrm{mM}$ silver nitrate and UV-Visible spectroscopic analysis. Further, the surface of the nanoparticles, its size, shape, physical nature and size distribution were studied using SEM, XRD and particle size analyser using zeta potential. The AgNPs synthesized from both the extracts were found to be of irregular shape and size, crystalline in nature and having less agglomeration due to the capping agents present in the extract. Also, FTIR results showed the presence of AgNPs and phytochemicals present in the extract which acts as reducing, capping and stabilizing agent. The antibacterial activity test shows that the AgNPs synthesized from the leaf-flower extract have higher antibacterial activity against oral pathogens than AgNPs formed from flower extract. From the present study, it can be concluded that the AgNPs synthesized from leaf-flower extract are more effective than the AgNPs from the flower extract of Tridax procumbens which makes it suitable for alternate new antibacterial agent. This LeafFlower extract AgNPs combination can be used as ingredients in toothpaste, toothbrushes, mouth wash etc. however after effectively testing them for Cytotoxicity studies. We believe that this could remove dental plaques effectively without causing any health problems for human beings and thereby a Plausible antimicrobial agent.

\section{Conflict of Interest}

On behalf of all authors, the corresponding author states that there is no conflict of interest.

\section{REFERENCES}

1 Vastrad, J. V., Goudar, G.: 'Green synthesis and characterization of silver nanoparticles using leaf extract of Tridax procumbens'Orient. J. Chem., 2016, 32, (3), pp. 1525-1530.

2 Singh, V.: 'Antimicrobial resistance', in 'Microbial pathogens and strategies for combating them: science, technology and education' (2013), pp. 291-296

3 Manonmani, V., Juliet, V.: 'Biosynthesis of silver nanoparticles foe the detection of pathogenic bacteria in food.', in 'Int Conf Innov Manag Serv IPEDR' (2011), pp. 307-311

Fritts, M., Crawford, C.C., Quibell, D., et al.: 'Traditional Indian medicine and homeopathy for HIV/AIDS: a review of the literature'AIDS Res. Ther., 2008, 5, (1), p. 25.

5 Kalishwaralal, K., Deepak, V., Ram Kumar Pandian, S., et al.: 'Biosynthesis of silver and gold nanoparticles using Brevibacterium casei' Colloids Surfaces B Biointerfaces, 2010, 77, (2), pp. 257-262.

6 Ramya, M., Subapriya, M.S.: 'Green synthesis 
of silver nanoparticles.'Int J Pharm Med Biol Sci, 2012, 1, (1), pp. 54-61.

7 Christudas, S., Kulathivel, T.M., Agastian, P.: 'Phytochemical and antibacterial studies of leaves of Tridax procumbens L.'Asian Pac. J. Trop. Biomed., 2012, 2, (1 SUPPL.), pp. S159-S161.

8 Mundada, S., Shivhare, R.: 'Pharmacology of Tridax procumbens a weed: Review' (2010), 2, pp. 1391-1394

9 C. Ikewuchi, J., C. Ikewuchi, C., M. Igboh, N., Ikewuchi J, C., Ikewuchi C, C., Igboh Ngoz, M.: 'Chemical Profile of Tridax procumbens Linn'Pakistan J. Nutr., 2009, 8, (5), pp. 548-550. Ganju, K., Pathak, A.K.: 'Pharmacognostic And Phytochemical Evaluation of Tridax procumbens Linn.'J. Pharmacogn. Phytochem., 2013, 1, (5), pp. 42-46.

11 Dhanalakshmi, T., Rajendran, S.: 'Synthesis of silver nanoparticles using Tridax procumbens and its antimicrobial activity'Sch. Res. Libr. Arch. Appl. Sci. Res., 2012, 4, (3), pp. 1289-1293.

12 Sangeetha R, N, P., N, D.: 'Characterization of silver nanoparticles synthesized using the extract of the leaves of Tridax procumbens'Res. J. Med. Plant, 2016, 10, (2), pp. 159-166.

13 Bhati-Kushwaha, H., Malik, C.P.: 'Assessment of antibacterial and antifungal activities of silver nanoparticles obtained from the callus extracts (stem and leaf) of Tridax procumbens L'Indian J. Biotechnol., 2014, 13, (1), pp. 114-120.

14 Munson, M.A., Banerjee, A., Watson, T.F., Wade, W.G.: 'Molecular analysis of the microflora associated with dental caries'J. Clin. Microbiol., 2004, 42, (7), pp. 3023-3029.

15 Rawashdeh, R., Haik, Y.: 'Antibacterial Mechanisms of Metallic Nanoparticles: A Review'Dyn. Biochem. Process Biotechnol. Mol. Biol., 2009, 3, (2), pp. 12-20.

16 Sundarrajan, M., A, J., S, J.: 'Morphology studies on silver nanoparticles synthesized bt green method using Tridax procumbens and Ocimum tenuiflorum leaf extracts.'Int. J. Innov. Res. Adv. Eng., 2017, 9, (4), pp. 50-54.

17 Sahu, N., Soni, D., Chandrashekhar, B., Sarangi, B.K., Satpute, D., Pandey, R.A.: 'Synthesis and characterization of silver nanoparticles using Cynodon dactylon leaves and assessment of their antibacterial activity'Bioprocess Biosyst. Eng., 2013, 36, (7), pp. 999-1004.

18 Bhati-Kushwaha, H., Malik, C.P.: 'Biosynthesis of silver nanoparticles using fresh extracts of Tridax procumbens Linn'Indian J. Exp. Biol., 2014, 52, (4), pp. 359-368. 